\title{
Pharmacological Options to Trigger Final Oocyte Maturation in In Vitro Fertilization
}

\author{
Sheetal G Sawankar ${ }^{1}$, Jaideep Malhotra ${ }^{2}$, Neharika M Bora ${ }^{3}$, Pinky R Shah ${ }^{4}$, Narendra Malhotra ${ }^{5}$
}

\begin{abstract}
Human chorionic gonadotropin (hCG) has been the gold standard in the induction of final oocyte maturation since the pioneer days of in vitro fertilization (IVF). But owing to its long half-life, it leads to increased risk of ovarian hyperstimulation syndrome (OHSS). Trigger of GnRH agonist is a more physiological trigger, effective, and safe, as it significantly reduces or eliminates risk of OHSS. Newer options of dual trigger and double trigger are discussed in this review, which can be used as modified luteal phase support in patients with expected suboptimal oocyte maturation. Newer pharmaceutical options such as Kissepeptins, key in central regulation of neuroendocrine system, and GnRH release need more studies before being implemented in general practice. This review includes details of various trigger options for final oocyte maturation and about combination of trigger options aiming safe and effective outcomes.
\end{abstract}

Keywords: Dual trigger, GnRH agonist, Human chorionic gonadotropin trigger, Kisspeptins, Ovarian hyperstimulation syndrome.

Journal of South Asian Federation of Obstetrics and Gynaecology (2020): 10.5005/jp-journals-10006-1753

\section{INTRODUCTION}

One in six couples are affected by infertility, and it has been recognized as the fifth serious global disability by the World Health Organization (WHO). ${ }^{1}$ In vitro fertilization (IVF) is the process in which controlled ovarian stimulation is done with gonadotropins in their pharmacological dose, while premature luteal hormone (LH) surge is prevented by either $\mathrm{GnRH}$ agonist or antagonist protocol. Since many years, human chorionic gonadotropin (hCG) has been used to induce final maturation and ovulation as surrogate to endogenous $\mathrm{LH}^{2}$ Ovum pickup to retrieve oocytes is timed after adequate $\mathrm{LH}$ exposure but prior to ovulation. After adequate $\mathrm{LH}$ exposure, there occurs initiation of resumption of meiosis oocyte maturation and attainment of fertilization competence. Under LH exposure, corpus luteum is formed by the remaining part of the follicle, which releases sex steroids, mainly progesterone, pivotal in preparing endometrium for implantation. ${ }^{3}$ Various triggers available for inducing oocyte maturation are hCG, GnRH agonist, recombinant $\mathrm{LH}$, and recently Kissepeptins.

Human chorionic gonadotropin trigger, owing to its long half-life and its luteotropic action, increases the risk of ovarian hyper stimulation syndrome (OHSS). GnRH agonist, although a physiological trigger causing surge of both $\mathrm{LH}$ and folliclestimulating hormone ( $\mathrm{FSH}$ ) and safe in polycyctic ovarian syndrome (PCOS) patients due to short LH surge, has inadequate luteal phase due to luteolysis of follicles, resulting in decrease in pregnancy rates. $\mathrm{GnRH}$ agonist trigger being safe, effective, and physiologic has shifted the IVF practice. Agent for oocyte maturation should be safe and efficacious in terms in pregnancy rates. Thus, the recently concept of dual trigger and double trigger has been introduced combining hCG and GnRH agonist. Individualization of choosing single agent or combination trigger will optimize safety and results of IVF.

\section{Physiology of Oocyte Maturation}

- Natural cycle LH surge leads to meiotic maturation, disruption of cumulus oocyte complex and ovulation, luteinization of

\begin{abstract}
${ }^{1}$ Morpheus life Sciences (Pvt) Limited, Mumbai, Maharashtra, India
${ }^{2}$ ART Rainbow IVF, Agra, Uttar Pradesh, India; Dubrovnik International University, Dubrovnik, Croatia

${ }^{3}$ Rainbow IVF Hospital, Agra, Uttar Pradesh, India; Patankar Hospital, Pune, Maharashtra, India

${ }^{4}$ Aarush IVF and Endoscopy Center, Mumbai, Maharashtra, India

${ }^{5}$ Global Rainbow Healthcare, Agra, Uttar Pradesh, India; Dubrovnick International University, Dubrovnik, Croatia; IAN Donald School, Mumbai, Maharashtra, India
\end{abstract}

Corresponding Author: Narendra Malhotra, Global Rainbow Healthcare, Agra, Uttar Pradesh, India; Dubrovnick International University, Dubrovnik, Croatia; IAN Donald School, Mumbai, Maharashtra, India, Phone: +919837033335, e-mail: mnmhagra3@ gmail.com

How to cite this article: Sawankar SG, Malhotra J, Bora NM, et al. Pharmacological Options to Trigger Final Oocyte Maturation in In Vitro Fertilization. J South Asian Feder Obst Gynae 2020;12(1):38-44.

Source of support: Nil

Conflict of interest: None

granulosa cells, and formation of corpus luteum that releases sex steroids for luteal phase support.

- Human oocytes are arrested at the prophase of the first meiotic division until the preovulatory LH surge, and oocyte maturation is a critical process to the success of IVF treatment, during which the oocyte gains competence for fertilization

- Oocyte maturation is initiated by LH-like exposure that can be provided by hCG, GnRH agonist, recombinant LH, or kisspeptin.

- Oocyte maturation is combination of nuclear and cytoplasmic maturation.

- Nuclear maturation (chromosomal segregation) is maturation of oocyte from metaphase I (immature stage) to metaphase II (mature stage), along with extrusion of first polar body, due to fall in intra-oocyte cyclic adenosine monophosphate (cAMP) concentration under LH exposure. ${ }^{3}$ The diploid cell transitions

(0) The Author(s). 2020 Open Access This article is distributed under the terms of the Creative Commons Attribution 4.0 International License (https://creativecommons. org/licenses/by-nc/4.0/), which permits unrestricted use, distribution, and non-commercial reproduction in any medium, provided you give appropriate credit to the original author(s) and the source, provide a link to the Creative Commons license, and indicate if changes were made. The Creative Commons Public Domain Dedication waiver (http://creativecommons.org/publicdomain/zero/1.0/) applies to the data made available in this article, unless otherwise stated. 
to haploid gamete and attains competence for fertilization by the haploid spermatozoa.

- Cytoplasmic maturation is associated with changes in dynamics of cytoskeleton, organelle redistribution, calcium release activity, and storage of $\mathrm{mRNA}$, transcription factor and proteins. This creates asymmetry enabling polar body extrusion with minimal loss of cytoplasm. ${ }^{4}$

- The resumption of meiosis is signaled by germinal vesicle breakdown (GVBD), and the interval between $\mathrm{LH}$ receptor activation and first stage of meiosis is 18 hours $^{5}$

- Total duration of nuclear maturation including time to GVBD is estimated to be 20 to 22 hours $^{6}$

\section{Options Available to Trigger Final Oocyte Maturation}

Options are shown in Flowchart 1 below.

\section{Description of Various Trigger Options}

hCG trigger: It has been pioneer for inducing final oocyte maturation, luteinization of granulosa cells, resumption of meiosis since decades, and as surrogate for natural midcycle LH surge.

- hCG binds to same receptor due to biological and structural similarity to natural LH (share same alpha subunit and $85 \%$ of amino acid structure of beta subunit) ${ }^{7}$ and can activate the same receptor to mimic action of natural LH surge.

- It allows progesterone secretion by promoting maintenance of corpus luteum.

- It may be linked in peri-trophoblastic immune tolerance development, thus facilitating trophoblastic invasion, expediting fetal development in the endometrium. ${ }^{8}$

\section{Difference between $h C G$ and $L H$}

The main difference is the half-life, approximately 60 minutes $^{9}$ for LH, while hCG has long half-life $>24$ hours. ${ }^{10}$ Human chorionic gonadotropin can lead to life-threatening condition such as OHSS. Activation of $\mathrm{LH}$ receptor by $\mathrm{hCG}$ and $\mathrm{LH}$ is not equivalent due to difference in intracellular signaling and kinetics. LH has more effect on antiapoptotic extracellular proliferative signaling, related kinase $1 / 2$, and AKT, while hCG has more CAMP and steriodogenic action. ${ }^{11}$

\section{Dose of hCG Trigger}

$5,000-10,000$ units of urinary hCG (intramuscular) or recombinant hCG 250-500 $\mu \mathrm{g}$ (subcutaneously).
Duration of hCG surge is dose dependent ${ }^{12}$ ( 0 hours for 100 IU, 24 hours for $300 \mathrm{IU}$, and 48 hours for $1000 \mathrm{IU})$, although lower doses can induce oocyte maturation, granulosa cell luteinization but are insufficient in ensuring optimal cytoplasmic maturation and adequate corpus luteum function. Thus, higher dose of hCG can influence duration at which hCG levels can be maintained above threshold and amplitude of hCG level can be attained.

$5,000 \mathrm{IU}$ as the minimum effective dose of $\mathrm{u}$-hCG and oocyte yield [(number of oocytes divided by number of follicles $14 \mathrm{~mm}$ )] did not increase in doses $>5,000 \mathrm{IU}^{13}$

Dose less than 2,000 IU of urinary hCG has less probability of retrieving oocytes and has increased chance of cycle cancelation, failed or low fertilization, or no embryos available to transfer. ${ }^{14}$ Higher doses of hCG can be beneficial in patients with higher body mass index (BMI) for efficacious triggering. ${ }^{15}$

Systematic review concluded that the clinical outcomes were similar between women receiving 5,000 or 10,000 IU of u-hCG. The incidence of OHSS was not reduced in the high-risk population even with lower dose of $\mathrm{u}$-hCG. The dose of $\mathrm{u}$-hCG for final oocyte maturation in women referred for IVF needs to be individualized. ${ }^{16}$

\section{Difference between uhCG and rhCG}

\section{$250 \mu \mathrm{g}$ of rec hCG is equivalent to $10,000 \mathrm{IU}$ of hCG}

- Urinary hCG has more impurities, batch to batch variability, and risk of leading to immunological reaction.

- Rec hCG is filled by mass, offer better dose precision and low batch to batch variability, contamination free, allows subcutaneous administration, and is better tolerated by patients.

Driscoll et al. in phase III double-blind randomized trial found no difference in number of oocytes retrieved: $>10 \mathrm{~mm}$ per follicle on day of trigger, number of mature oocytes, number of cleaved embryos in rhCG verses uhCG groups. ${ }^{17} \mathrm{~A}$ larger randomized controlled study done on 297 patients found no difference in number of oocytes following 10,000 of uhCG, 250 Mg of rhCG, or $500 \mu \mathrm{g} \mathrm{rhCG}$. The authors found two more zygotes/cleaved embryos in the $500-\mu \mathrm{g}$ rhCG group than the $250-\mu \mathrm{g}$ rhCG with increased risk of OHSS ( $9 \%$ vs $3 \%$ ] in the former. The authors thus recommended $250 \mu \mathrm{g}$ rhCG for clinical use due to convenience and lower risk of OHSS. ${ }^{18}$ Cochrane review which included 18 studies in 2,952 women undergoing IVF or intracytoplasmic sperm injection found no difference between rhCG and uhCG or between RhLH and uhCG in rates of live birth/ongoing pregnancy or OHSS. ${ }^{19}$

Flowchart 1: Various options to trigger oocyte maturation

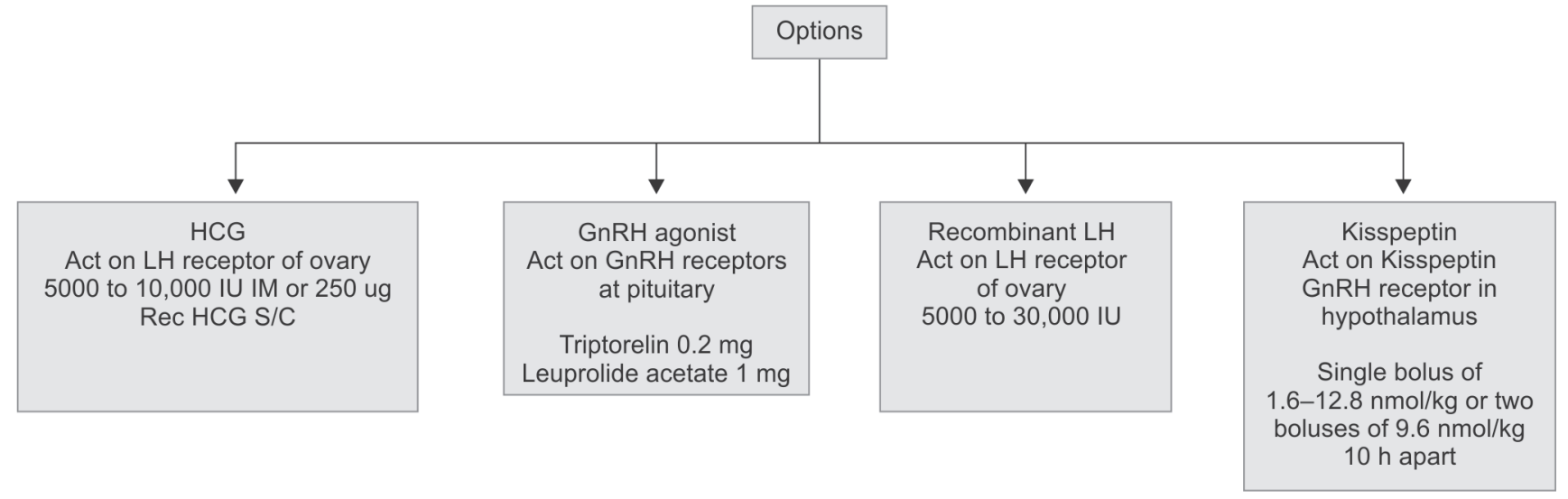


OHSS risk is high with hCG trigger due to:

- Long half-life

- Luteotropic action

- Due to its direct action on stimulated follicles, it causes release of vasoactive compounds mainly vascular endothelial growth factor (VEGF). Angiongenic factors lead to third space accumulation and depletion of intravascular volume. Fluid shift to interstitial spaces causes pleural effusion, ascites, hypotension, oliguria, thromboembolism. and organ failure $\mathrm{e}^{20}$

GnRH agonist trigger: Nakano et al. first described it as option to induce final maturation. ${ }^{21}$ With introduction of $\mathrm{GnRH}$ antagonist protocols, GnRH agonist was considered an option due to fact that antagonist has short duration and rapid irreversible action, thus allowing receptor to be active to $\mathrm{GnRH}$ agonist single bolus action

GnRH surge vs natural LH surge: GnRH agonist surge lasts for 24-36 hours and comprises only two phases of short ascending limb (lasting 4 hours) and long descending limb (lasting 20 hours) ${ }^{22}$ in contrast to natural midcycle LH surge which lasts for 48 hours and consists three phases. ${ }^{23}$ This difference has striking role in reduction of risk of OHSS, owing to shorter duration of endogenous $\mathrm{LH}$ surge ${ }^{24}$ (Flowchart 2).

\section{Advantages of GnRH Agonist Trigger}

- GnRH agonist is considered to be a physiological trigger, as it induces release of both FSH and LH after displacing antagonist and activating the receptor. This flare effect is comparable to natural midcycle surge of gonadotropins. ${ }^{21}$

- Simultaneous FSH surge promotes LH receptor formation on granulosa cells, cumulus expansion, and nuclear maturation, and synergist action with LH promotes final oocyte maturation and provides optimal environment. ${ }^{25}$

- It eliminates severe OHSS in combination owing to rapid and reversible luteolysis and inhibits secretion of vasoactive compounds mainly VEGF from the corpus luteum. Largest randomized trial in population at risk of OHSS (follicles 15-25) found no case of OHSS despite low-dose hCG rescue, followed by doing fresh embryo transfer and showed comparable reproductive outcome to hCG. $^{26}$

- It is preferred in PCOS patients (follicles $>25$ ) to eliminate risk of OHSS: Segmented IVF (cryopreservation of embryos and transferring on later date).

- Fertility preservation: There is need to avoid high estradiol levels in these patients, and thus $\mathrm{GnRH}$ agonist with antagonist protocol is preferred. GnRH eliminates OHSS, gives more metaphase ll oocytes, and thus more embryos. It can be used in

Flowchart 2: Difference between GnRH and natural LH surge

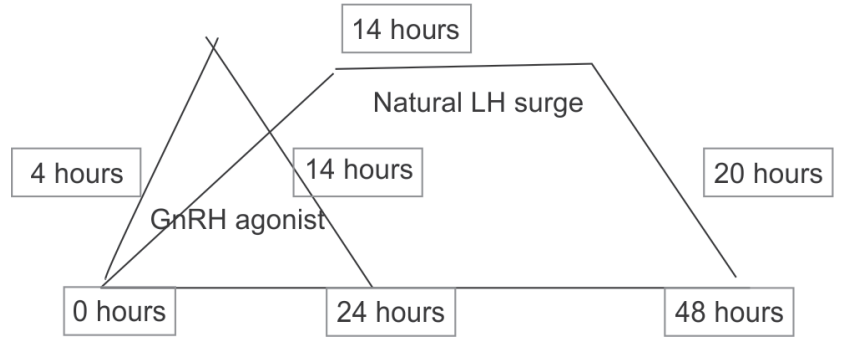

random start protocols reducing the waiting period, as pituitary is capable to respond sufficiently in luteal phase.

- It is preferred in oocyte donors for final oocyte maturation and results in retrieval of oocytes of similar quality to hCG and hence gives similar results in recipient, eliminating the risk of severe OHSS. ${ }^{27}$ It simplifies egg donor program for clinician, as it eliminates the need for estradiol monitoring during stimulation, and post-OPU decreases the burden of follow-up owing to short luteal phase (4-6 days), reduced ovarian volume, and much diminished abdominal distension in donors.

\section{Dose for Final Oocyte Maturation}

Inj Triptorelin 0.2 mg, Inj leuprolide acetate $1 \mathrm{mg}$, Buserelin nasal spray $500 \mu \mathrm{g}$.

Parneix et al., in 231 women, compared different ovulation induction agents, including triptorelin, nafarelin, leuprolide, or hCG and concluded that all regimes lead to ovulation with no superiority of one analog to other in terms and gave similar pregnancy rates between test groups and the control hCG group. There is insufficient evidence in the literature to support any preference of one $\mathrm{GnRH}$ agonist agent over another, although the dosing may vary. ${ }^{28}$

Luteal phase after GnRH agonist trigger: Through pituitary downregulation, $\mathrm{GnRH}$ agonist reduces the levels of $\mathrm{LH}$, which is inadequate to support ongoing function of corpus luteum, thus leading to fall in serum progesterone and suboptimal implantation. Thus, duration of LH surge after agonist trigger is sufficient to induce oocyte maturation but not sufficient to maintain adequate corpus luteum. ${ }^{29}$ Thus, despite supplementation of adequate luteal phase support, there is reduction in pregnancy rates and increase in pregnancy loss due to luteal phase insufficiency.

Modified luteal phase support options with $\mathrm{GnRH}$ agonist trigger are:

- Low-dose hCG at time of oocyte retrieval: Single bolus of 1,500 IU of hCG along with standard luteal support. ${ }^{30}$

- Dual trigger: Low-dose hCG with GnRH agonist trigger, which rescues corpora lutea by giving additional signal required for luteinization.

- Very low doses of hCG: Recombinant hCG (125 IU) given daily starting during the stimulation cycle. ${ }^{31}$

- Intensive luteal support: To start with progesterone injection $50 \mathrm{mg}$ daily with three $0.1 \mathrm{mg}$ transdermal E2 patches, replaced every other day from day of oocyte retrieval. Serum levels closely monitored and dose adjustment done to maintain serum levels of progesterone $>20 \mathrm{ng} / \mathrm{mL}$ and serum estradiol $>200 \mathrm{pg} / \mathrm{mL}^{32}$

- Recombinant LH: Given as $300 \mathrm{IU}$, in six alternate doses starting from day of OPU along with $600 \mathrm{mg}$ daily vaginal progesterone. ${ }^{33}$

- Fixed low-dose hCG: Three fixed doses of $500 \mathrm{IU}$ administered every third day along with progesterone supplementation starting form day of OPU. ${ }^{34}$

\section{Recombinant $L H$}

Given in dose of 5,000 to 30,000 IU subcutaneously.

It is as effective as 5,000 IU hCG and more safe, as risk of OHSS is nil. Multicentric double-blind trial showed single dose of rh-LH is effective in inducing final follicular maturation and early luteinization in IVF and embryo transfer patients and is comparable to $5,000 \mathrm{IU}$ u-hCG, with significant reduction in OHSS. The dose 
of rh-LH giving the highest efficacy to safety ratio was between 15,000 and $30,000 \mathrm{IU} .^{35}$

It is not routinely used as it is expensive and cumbersome in administration. Data on rise of $\mathrm{LH}$ in first 24 hours are not clear, and thus timing of oocyte retrieval may not be optimal and offers no additional advantage over hCG.

Kisspeptins: They are recently discovered peptide hormones that play a role in regulation of neuro-endocrinology of human reproduction. Kisspeptins are potent stimulators of the hypothalamic-pituitarygonadal axis. ${ }^{36}$ They signal directly to $\mathrm{GnRH}$ neurons, leading to release of $\mathrm{GnRH}$ in the portal circulation, which in turn leads secretion of both FSH and LH from the anterior pituitary. ${ }^{37}$

Preliminary studies are in favor of using Kisspeptins in practice for final oocyte maturation. Abbara at al. concluded that kisspeptins can be used as natural pharmacologic option for induction of ovulation due its effectiveness in eliciting LH surge for final oocyte maturation, with successful live births and importantly eliminating risk of OHSS. ${ }^{38}$

Dosing: Kisspeptin-54 in single bolus of 1.6 to $12.8 \mathrm{nmol} / \mathrm{kg}$ or two boluses of $9.6 \mathrm{nmol} / \mathrm{kg} 10$ hour apart (16-18). ${ }^{39}$

\section{Criteria to be Fulfilled for Giving Ovulation Trigger}

Trigger is usually given when two or three follicles are $>17 \mathrm{~mm}$ on ultrasound monitoring and/or serum estradiol in range of 1,500 to $3,000 \mathrm{pg} / \mathrm{mL}$ or 100 to $200 \mathrm{pg} / \mathrm{mL} /$ follicle

Follicles in range from 16 to $22 \mathrm{~mm}$ give maximum oocyte yield. ${ }^{40}$ The size of follicles at time of trigger influences likelihood of getting mature oocytes as diameter of the leading follicle provides representation of other follicles when they are growing in a tight cohort.

\section{Timing of Ovum Pickup in Terms of Trigger}

Ovum pickup is timed 35 hours after hCG trigger, as in some women ovulation was seen at 36 hours following administration of intramuscular hCG. ${ }^{41}$

A total of 533 patients undergoing IVF with long protocol, with interval ranging from 33 to 41 hours between uhCG and ovum pickup, were studied. No significant differences were observed in the ratio of oocytes retrieved divided by the number of follicles punctured in the interval groups (63.8\%: $33-<36$ hours, 60.9\%: 36-<38 hours, 62.5\%: 38-<41 hours). The author did not find significant differences in the number of oocytes retrieved, fertilization rates, or clinical pregnancy rates. ${ }^{42}$ In stimulated cycles, there is evidence to suggest that extending the interval between hCG administration and oocyte retrieval beyond the standard 41 hours is unlikely to lead to the frequent occurrence of premature ovulation; ${ }^{42}$ however, there is insufficient evidence to suggest if outcome will improve with longer intervals between ovum pickup and trigger. ${ }^{43}$ Option of double trigger explained subsequently highlights on flexibility of time between ovum pickup and trigger.

\section{Empty Follicle Syndrome}

This is frustrating to patients and clinicians and is characterized by lack of oocytes retrieved despite adequate ovarian response on ovarian stimulation and meticulous aspiration of follicles. It is classified as genuine and false empty follicle syndrome. Etiology can be uncertain in most cases after hCG could be due to human error in administration or pharmaceutical error. Although in one study incidence of EFS after hCG and GnRH agonist trigger (3.1\% vs 3.5\%, respectively) was reported to be similar, but there is difference in pathology due to difference in their site of action. ${ }^{44}$

Cases of EFS after hCG trigger in antagonist cycles are solved by changing to $\mathrm{GnRH}$ agonist, which being more physiological causes release of both $\mathrm{FSH}$ and $\mathrm{LH}$ promoting adequate follicular maturation and thus preventing EFS. ${ }^{45}$

\section{Suboptimal Response to GnRH Agonist Trigger}

In small subset of patients, there can be suboptimal response with inadequate oocyte yield following $\mathrm{GnRH}$ agonist trigger. This suboptimal response can range from much fewer oocytes than expected to empty follicle syndrome.

In PCOS patients, suboptimal response can be seen due to selfpriming of gonadotroph cells in pituitary by high E2 and suboptimal delivery of gonadotropins due to inadequate neovascularization owing to more number to intermediate follicles. Thus, post-GnRH agonist trigger, the resultant endogenous FSH and LH could be inadequate. Higher number of mature oocytes and higher pregnancy rates are seen after a repeat dose of $\mathrm{GnRHa}$ trigger 12-hour following the first dose due to maintenance of sustained level of gonadotropins. ${ }^{46}$

Poor outcome or canceled retrieval was seen in patients with serum LH $<15$ IU, 12 hours post-agonist trigger. Overall reported incidence of suboptimal response to $\mathrm{GnRH}$-a trigger was $5.2 \% .{ }^{47}$ Various risk factors found were baseline $\mathrm{LH}<0.1$, serum $\mathrm{LH}$ on day of trigger $<0.5$, long-term use of oral contraceptives, and low BMI hypothalamic dysfunction. In all, $25 \%$ chance of suboptimal response was seen when serum LH was undetectable on the day of trigger. It is recommended to individualized final oocyte maturation in patients with risk factors for having suboptimal response to $\mathrm{GnRH}$ a trigger. ${ }^{47}$ Role of dual trigger and double trigger that provide more sustained support of corpus luteum is explained further in the review. Human chorionic gonadotropin component in combination trigger acts as second rescue in such event of suboptimal response to $\mathrm{GnRH}$ agonist trigger.

\section{Dual Trigger}

Dual trigger was first defined as the concept of a combination of GnRH agonist and a low-dose hCG (1,000 to 2,500 IU) in triggering final oocyte maturation ${ }^{48}$ in high responder patients. There was absence of OHSS and acceptable fertilization, implantation, clinical and ongoing pregnancy rates, and early pregnancy loss. ${ }^{48}$ Role and application of dual trigger were further explored in various studies. Ding et al. conducted a meta-analysis including 527 women from four eligible RCTs to investigate the efficacy of the dual trigger in comparison to hCG alone (Schachter et al. ${ }^{49}$ in 2008, Decleer et al. ${ }^{50}$ in 2014, Kim et al. ${ }^{51}$ in 2014, Mahajan et al. ${ }^{52}$ in 2016). The analysis did not demonstrate any difference in the number of oocytes, mature oocytes, zygotes, or implantation rate, although it did find an increase in the pregnancy rate in the GnRHa-supplemented group when compared to hCG alone (relative risk, $1.55 ; 95 \% \mathrm{Cl}, 1.17-2.06) .{ }^{53}$ In summary, additional FSH exposure is suggested to enhance oocyte maturation, although LH/hCG plays a dominant role and the additional impact of FSH is likely to be small.

Advantages of dual trigger:

- GnRH component is more physiological and causes release of both endogenous FSH and LH and increases the number of mature oocytes retrieved, resulting in optimization of live births. 
- hCG component supports corpus luteum function and supports implantation.

- Potential enhancement of endometrial receptivity by the GnRH-a component.

- Dual combined trigger leads to higher levels amphiregulin and epiregulin (ligands of epidermal growth factor), which plays important role in cumulus expansion, ${ }^{54}$ oocytes maturation, ${ }^{55}$ and thus resumption of meiosis.

Large prospective trials are needed to exactly evaluate the role of dual trigger before routine implementation in practice in different groups of patients undergoing IVF.

\section{Double Trigger}

The concept of the "double trigger" represents a combination of a GnRH agonist and a standard hCG, when used 40 and 34 hours prior to ovum pickup, respectively. ${ }^{56}$

Double trigger prolongs the time between ovulation trigger and ovum pickup, aiming to overcome any existing granulosa cell dysfunction, facilitating cumulus cell expansion and meiotic maturation and thus results in retrieving more mature oocytes and plays role in patients with abnormal follicular maturation despite adequate response to $\mathrm{COH}$.

In patients with $<50 \%$ number of oocytes retrieved per number of dominant follicles on day of trigger, double trigger has led to significant increase in number of oocytes retrieved and number of high-quality embryos when compared to hCG alone. ${ }^{57}$ Double trigger has been offered in the treatment of patients with immature oocyte syndrome where less than $25 \%$ of the expected oocytes are retrieved or with poor/low oocytes yield and empty follicle syndrome. ${ }^{58}$

\section{Indications of Dual Trigger and Double Trigger}

- Previous history of $>25 \%$ immature oocytes retrieved

- Empty follicle syndrome

- To prevent OHSS in PCOS patients and get adequate luteal phase support in PCOS patients

- Poor responders

\section{Individualization of Combination Trigger}

- Normal responder: Combination of GnRH agonist with standard hCG bolus (5,000-10,000 IU) administered together and OPU done at 35-37 hours: significant increase in mature oocytes, number of good-quality embryos for transfer, and cryopreservation. ${ }^{59}$ It is not recommended if fresh embryo transfer is planned.

- Poor responder: Combination of GnRH agonist with standard hCG bolus (5,000-10,000 IU) administered together and OPU done at 34 hours $^{59}$ (improves oocyte yield).

- High responders: Increases mature oocyte yield, rescues corpus luteum improving pregnancy rates, and reduces OHSS rates.

- 15 to 25 follicles: Dual trigger in form of GnRH agonist and low-dose hCG 1,500 IU one hour post-oocyte retrieval with modified luteal phase support ${ }^{26}$

- Follicles <14: Concomitant GnRH agonist with 1,500 IU hCG for final oocyte maturation.

\section{ConCLUSION}

In this review article, we have reviewed different pharmacological options for triggering of final oocyte maturation in ART. Time has come in terms of individualization of choice of ovulation trigger for final maturation in ART. The risk of OHSS has been reduced from the time GnRHa trigger has been used for final oocyte maturation although hCG has been the gold standard for decades. The advantage of GnRHa trigger is segmentation of IVF in patients with high risk of OHSS, where a freeze all policy can be performed followed by frozen embryo transfer in the subsequent cycle to minimize the risk of OHSS and have a higher cumulative pregnancy rate. Also, depending on the number of oocytes retrieved, GnRHa trigger opens the possibility to tailor the luteal phase support.

Kisspeptins for final follicular maturation are in the horizon. The promising results of a preliminary study need to be further explored in large clinical trials.

\section{References}

1. World Health Organization, Prevalence of moderate and severe disability (in millions), by leading health condition associated with disability, and by age and income status of countries. Available at: www.who.int/reproductivehealth/topics/infertility/definitions/en/. Accessed on 1 November 2017.

2. Shoham Z, Schacter M, Loumaye E, et al. The luteinizing hormone surge - the final stage in ovulation induction: modern aspects of ovulation triggering. Fertil Steril 1995;64(2):237-251. DOI: 10.1016/ s0015-0282(16)57717-6.

3. Voronina E, Wessel G. The regulation of oocyte maturation. Curr Top Dev Biol 2003;58:53-110. DOI: 10.1016/s0070-2153(03)58003-6.

4. Mao L, Lou H, Lou Y, et al. Behaviour of cytoplasmic organelles and cytoskeleton during oocyte maturation. Reprod Biomed Online 2014;28(3):284-299. DOI: 10.1016/j.rbmo.2013.10.016.

5. Seibel MM, Smith DM, Levesque L, et al. The temporal relationship between the luteinizing hormone surge and human oocyte maturation. Am J Obstet Gynecol 1982;142(5):568-572. DOI: 10.1016/0002-9378(82)90763-3.

6. Escrich L, Grau N, de los Santos MJ, et al. The dynamics of in vitro maturation of germinal vesicle oocytes. Fertil Steril 2012;98(5): 1147-1151. DOI: 10.1016/j.fertnstert.2012.07.1116.

7. Hershko Klement A, Shulman A. hCG triggering in ART: an evolutionary concept. Int J Mol Sci 2017;18(5):E1075. DOI: 10.3390/ ijms18051075.

8. Kayisli UA, Selam B, Guzeloglu-Kayisli O, et al. Human chorionic gonadotrophin contributes to maternal immunotolerance and endometrial apoptosis by regulating fas-fas ligand system. J Immunol 2003;171(5):2305-2313. DOI: 10.4049/jimmunol.171.5.2305.

9. Yen SS, Llerena O, Little B, et al. Disappearance rates of endogenous luteinizing hormone and chorionic gonadotropininman. J Clin Endocrinolog Metabol 1968;28(12):1763-1767. DOI: 10.1210/jcem-2812-1763.

10. Damewood MD, Shen W, Zacur HA, et al. Disappearance of exogenously administered human chorionic gonadotropin. Fertil Steril 1989;52(3):398-400. DOI: 10.1016/s0015-0282(16)60906-8.

11. Casarini L, Riccetti L, De Pascali F, et al. Estrogen modulates specific life and death signals induced by LH and hCG in human primary granulosa cells in vitro. Int J Mol Sci 2017;18(5):926. DOI: 10.3390/ ijms18050926.

12. Zelinski-Wooten MB, Hutchison JS, TrinchardLugan I, et al. Initiation ofperiovulatoryeventsingonadotrophin-stimulated macaques with varying doses of recombinant human chorionic gonadotrophin. Hum Reprod 1997;12(9):1877-1885. DOI: 10.1093/humrep/12.9.1877.

13. Detti L, Mitwally MFM, Rode A, et al. Serum human chorionic gonadotropin level after ovulation triggering is influenced by the patient's body mass index and the number of larger follicles. Fertil Steril 2007;88(1):152-155. DOI: 10.1016/j.fertnstert.2006.11.124.

14. Abdalla HI, Ah-Moye M, Brinsden P, et al. The effect of the dose of human chorionic gonadotropin and the type of gonadotropin stimulation on oocyte recovery rates in an in vitro fertilization 
program. Fertil Steril 1987;48(6):958-963. DOI: 10.1016/s00150282(16)59591-0.

15. Matorras R, Meabe A, Mendoza R, et al. Human chorionic gonadotropin (hCG) plasma levels at oocyte retrieval and IVF outcomes. J Assist Reprod Genet 2012;29(10):1067-1071. DOI: 10.1007/ s10815-012-9826-7.

16. Tsoumpou Ioanna. Symposium: update on prediction and management of OHSS optimal dose of HCG for final oocyte maturation in IVF cycles: absence of evidence? Reproductive Bio Medicine Online 2009;19(1):52-58. DOI: 10.1016/s1472-6483(10)60045-4.

17. Driscoll GL, Tyler JP, Hangan JT, et al. A prospective, randomized, controlled, double-blind, double-dummy comparison of recombinant and urinary HCG for inducing oocyte maturation and follicular luteinization in ovarian stimulation. Hum Reprod 2000;15(6): 1305-1310. DOI: 10.1093/humrep/15.6.1305.

18. Chang $P$, Kenley $S$, Burns $T$, et al. Recombinanthumanchorionic gonadotropin (rhCG) in assisted reproductive technology: Results of a clinical trial comparing two dosesofrhCG(Ovidrel) tourinaryhCG(Profasi) for induction of final follicular maturation in in vitro fertilization-embryo transfer. Fertil Steril 2001;76(1):67-74. DOI: 10.1016/s0015-0282(01)01851-9.

19. Youssef $\mathrm{M}, \mathrm{Al}$-inany $\mathrm{H}$, Aboulghar $\mathrm{M}$, et al. Recombinant versus urinary human chorionic gonadotrophin for final oocyte maturation triggering in IVF and ICSI cycles. Cochrane Database Syst Rev 2016;4:CD003719. DOI: 10.1002/14651858.CD003719.pub4.

20. Budev MM, Arroliga AC, Falcone T. Ovarian hyperstimulation syndrome. Crit Care Med 2005;33(10):301-306. DOI: 10.1097/01. ccm.0000182795.31757.ce.

21. Nakano R, Mizuno T, Kotsuji F, et al. Triggering' of ovulation after infusion of synthetic luteinizinghormone releasing factor(LRF). Acta Obstetriciaet Gynecologica Scandinavica 1973;52(3):269-272. DOI: 10.3109/00016347309158325.

22. Itskovitz J, Boldes R, Levron J, et al. Induction of preovulatory luteinizing hormone surgeand prevention of ovarian hyperstimulation syndrome by gonadotropin-releasing hormone agonist. Fertil Steril 1991;56(2):213-220. DOI: 10.1016/S0015-0282(16)54474-4.

23. Hoff JD, Quigley ME, Yen SSC. Hormonaldynamics at midcycle: a reevaluation. J Clin Endocrinol Metabol 1983;57(4):792-796. DOI: 10.1210/jcem-57-4-792.

24. Kol S. Luteolysis induced by a gonadotropin-releasing hormone agonist is the key to prevention of ovarian hyperstimulation syndrome. Fertil Steril 2004;81(1):1-5. DOI: 10.1016/j.fertnstert.2003. 05.032 .

25. Zelinski-Wooten MB, Hutchison JS, Hess DL, et al. Follicle stimulating hormone alone supports follicle growth and oocyte development in gonadotrophin releasing hormone antagonist-treated monkeys. Hum Reprod 1995;10(7):1658-1666. DOI: 10.1093/oxfordjournals. humrep.a136151.

26. Humaidan P, Polyzos NP, Alsbjerg B, et al. GnRHa trigger and individualized luteal phase $\mathrm{hCG}$ support according to ovarian response to stimulation: Two prospective randomized controlledmulticentrestudiesin IVF patients. Hum Reprod 2013;28(9):2511-2521. DOI: 10.1093/humrep/det249.

27. Melo M, Busso C, Bellver J, et al. GnRH agonist versus recombinant HCG in an oocyte donation programme: a randomized, prospective, controlled, assessor-blindstudy. Reproduct Bio Med Online 2009;19(4):486-492. DOI: 10.1016/j.rbmo.2009.06.001.

28. Parneix I, Emperaire JC, Ruffie A, et al. Comparaisondediff'erentspr otocolesded'eclenchement de l'ovulation, par agonistes du GnRH et gonadotrophine chorionique. Gyn'ecol Obst'et Fertil 2001;29(2): 100-105. DOI: 10.1016/S1297-9589(00)00064-3.

29. Andersen CY, Andersen KV. Improving the luteal phase after ovarian stimulation: reviewing new options. Reprod Biomed Online 2014;28(5):552-559. DOI: 10.1016/j.rbmo.2014.01.012.

30. Humaidan P. Luteal phase rescue in high-risk OHSS patients by GnRHa trig-gering in combination with low-dose HCG: a pilot study. Reprod Biomed Online 2009;18(5):630-634. DOI: 10.1016/s14726483(10)60006-5.
31. Andersen CY, Elbaek HO, Alsbjerg B, et al. Daily low-dose hCG stimulation during the luteal phase combinedwith GnRHa triggered IVF cycles without exogenous progesterone: a proofof concept trial. Hum Reprod 2015;30(10):2387-2395. DOI: 10.1093/humrep/ dev184continued daily through the luteal phase.

32. Engmann L, DiLuigi A, Schmidt $D$, et al. The use ofgonadotropinreleasing hormone $(\mathrm{GnRH})$ agonist to induce oocyte maturation after cotreatment with GnRH antagonist in high-risk patients undergo-ing in vitro fertilization prevents the risk of ovarian hyperstimulationsyndrome: a prospective randomized controlled study. Fertil Steril 2008;89(1):84-91. DOI: 10.1016/ j.fertnstert.2007.02.002.

33. Papanikolaou EG, Verpoest W, Fatemi $H$, et al. A novel method of luteal supplementation with recombinant luteinizing hormone when a gonadotropin-releasing hormone agonist is used instead of human chorionic gonadotropin for ovulation triggering: a randomized prospective proof of concept study. Fertil Steril 2011;95(3):1174-1177. DOI: 10.1016/j.fertnstert.2010.09.023.

34. Castillo JC, Dolz M, Bienvenido E, et al. Cycles triggered with GnRH agonist: exploring low-dose HCG for luteal support. Reprod Biomed Online 2010;20(2):175-181. DOI: 10.1016/j.rbmo.2009.11.018.

35. European Recombinant LH Study Group. Human recombinant luteinizing hormone is as effective as, but safer than, urinary humanchorionic gonadotropin in inducing final follicular maturation and ovulation in in vitro fertilization procedures: results of a multicenter double-blind study. J Clin Endocrinol Metab 2001;86(6):2607-2618. DOI: 10.1210/jcem.86.6.7599.

36. Seminara SB, Messager S, Chatzidakietal EE. The GPR54 gene as a regulator of puberty. N Engl J Med 2003;349(17):1614-1627. DOI: 10.1056/NEJMoa035322.

37. Skorupskaite K, George JT, Anderson RA. The kisspeptins-GnRH pathway in human reproductive healthand disease. Hum Reprod Update 2014;20(4):485-500. DOI: 10.1093/humupd/dmu009.

38. Abbara, Jayasena CN, Nijher GK, Kisspeptins-a novel physiological trigger for oocytematuration in IVF treatment, Human Reproduction; Supplement 1; European Society of Human Reproduction and Embryology 29th Annual Meeting, London, Abstract O-107, 2013.

39. Abbara A, Jayasena CN, Christopoulos G, et al. Efficacy of kisspeptin-54 to trigger oocyte maturation in women at high risk of ovarian hyperstimulation syndrome (OHSS) during in vitro fertilization (IVF) therapy. J Clin Endocrinol Metab 2015;100(9):3322-3331. DOI: 10.1210/ jc.2015-2332.

40. Revelli A, Martiny G, Delle Piane L, et al. A critical review of bidimensional and three-dimensional ultrasound techniques to monitor follicle growth: do they help improving IVF outcome? Reprod Biol Endocrinol 2014;12(1):107. DOI: 10.1186/1477-7827-12-107.

41. Nader S, Berkowitz AS. Study of the pharmacokinetics of human chorionic gonadotropin and its relation to ovulation. J in Vitro Fert Embryo Transf 1990;7(2):114-118. DOI: 10.1007/BF01135585.

42. Nargund G, Reid F, Parsons J. Human chorionic gonadotropinto-oocyte collection interval in a superovulation IVF program. A prospective study. J Assist Reprod Genet 2001;18(2):87-90. DOI: 10.1023/a:1026530624575.

43. Ghasemian F, Faraji R, Asgharnia M, et al. The impact of different time intervals between hCG priming and oocyte retrieval on ART outcomes. Iran J Reprod Med 2013;11(7):559-564.

44. Castillo JC, Garcia-Velasco J, Humaidan P. Empty follicle syndrome after GnRHa triggering versus hCG triggering in COS. J Assist Reprod Genet 2012;29(3):249-253. DOI: 10.1007/s10815-011-9704-8.

45. Lok F, Pritchard J, Lashen $\mathrm{H}$. Successful treatment of empty follicle syndrome by triggering endogenous LH surge using GnRH agonist in an antagonist down-regulated IVF cycle. Human Reproduction, 2003;18(10):2079-2081. DOI: 10.1093/humrep/deg421.

46. Deepika K, Baiju P, Gautham P, et al. Repeat dose of gonadotropinreleasing hormone agonist trigger in polycystic ovarian syndrome undergoing in vitro fertilization cycles provides a better cycle outcome - a proof-of-concept study. J Hum Reprod Sci [serial online] 2017;10(4):271-280. DOI: 10.4103/jhrs.JHRS_102_17. 
47. Meyer L, Murphy LA, Gumer A, et al. Risk factors for a suboptimal response to gonadotropin-releasing hormone agonist trigger during in vitro fertilization cycles. Fertil Steril 2015;104(3):637-642. DOI: 10.1016/j.fertnstert.2015.06.011.

48. Shapiro BS, Daneshmand ST, Garner FC, et al. Gonadotropin-releasing hormone agonist combined with a reduced dose of human chorionic gonadotropin for final oocyte maturation in fresh autologous cycles of in vitro fertilization. Fertil Steril 2008;90(1):231-233. DOI: 10.1016/ j.fertnstert.2007.06.030.

49. Schachter M, Friedler S, Ron-El R, et al. Can pregnancy rate be improved in gonadotropin-releasing hormone $(\mathrm{GnRH})$ antagonist cycles by administering GnRH agonist before oocyte retrieval? A prospective, randomized study. Fertil Steril 2008;90(4):1087-1093. DOI: 10.1016/j.fertnstert.2007.07.1316.

50. Decleer W, Osmanagaoglu K, Seynhave B, et al. Comparison of hCG triggering versus hCG in combination with a GnRH agonist: a prospective randomized controlled trial. Facts Views Vis Obgyn 2014;6(4):203-209.

51. Kim CH, Ahn JW, You RM, et al. Combined administration of gonadotropin- releasing hormone agonist with human chorionic gonadotropin for final oocyte maturation in $\mathrm{GnRH}$ antagonist cycles for in vitro fertilization. J Reprod Med 2014;59(1-2): 63-68.

52. Mahajan N, Sharma S, Arora PR, et al. Evaluation of dual trigger with gonadotropin-releasing hormone agonist and human chorionic gonadotropin in improving oocyte maturity rates: a prospective randomized study. J Hum Reprod Sci 2016;9(2):101-106. DOI: 10.4103/0974-1208.183506.
53. Ding N, Liu X, Jian Q, et al. Dual trigger of final oocyte maturation with a combination of $\mathrm{GnRH}$ agonist and $\mathrm{hCG}$ versus a $\mathrm{hCG}$ alone trigger in $\mathrm{GnRH}$ antagonist cycle for in vitro fertilization: a systematic review and meta-analysis. Eur J Obstet Gynecol Reprod Biol 2017;218:92-98. DOI: 10.1016/j.ejogrb.2017.09.004.

54. Caixeta ES, Machado MF, Ripamonte P, et al. Effects of FSH on the expression of receptors for oocyte-secreted factors and members of the EGF-like family during in vitro maturation in cattle. Reprod Fertil Dev 2013;25(6):890-899. DOI: 10.1071/RD12125.

55. Park JY, Su YQ, Ariga M, et al. EGF-like growth factors as mediators of LH action in the ovulatory follicle. Science 2004;303(5658):682-684. DOI: 10.1126/science.1092463.

56. Kasum M, Kurdija K, Orešković S, et al. Combined ovulation triggering with GnRH agonist and hCG in IVF patients. Gynecol Endocrinol 2016;32(11):861-865. DOI: 10.1080/09513590.2016.1193141.

57. Haas J, Zilberberg E, Dar S, et al. Co-administration of GnRH-agonist and hCG for final oocyte maturation (double trigger) in patientswith low number of oocytes retrieved per number of preovulatory follicles-apreliminary report. J Ovarian Res 2014;7(1):77. DOI: 10.1186/1757-2215-7-77.

58. Griffin D, Benadiva C, Kummer N, et al. Dual trigger of oocyte maturation with gonadotropin-releasing hormone agonist and low-dose human chorionic gonadotropin to optimize live birth rates in high responders. Fertil Steril 2012;97(6):1316-1320. DOI: 10.1016/ j.fertnstert.2012.03.015.

59. Orvieto R. Triggering final follicular maturation- $\mathrm{hCG}, \mathrm{GnRH}$-agonist or both, when and to whom? Orvieto Journal of Ovarian Research 2015;8(1):60. DOI: 10.1186/s13048-015-0187-6. 